\title{
Multiple linear regression for the analysis of the parameters used in dyes decolourisation by ozonation techniques
}

\author{
Siti Fatimah ${ }^{1, *}$, and Wiharto Wiharto ${ }^{2}$ \\ ${ }^{1}$ Department of Chemical Engineering, Muhammadiyah University of Surakarta, Indonesia. \\ ${ }^{2}$ Department of Informatic, Sebelas Maret University, Surakarta, Indonesia
}

\begin{abstract}
The ozonation process of dye Acid Orange 7 (AO7), Acid Yellow 19 (AY19), and Acid Black 1 (AB1) have been performed. The experimental results predicted the magnitude of the influence of each variable by using Multiple Linear Regression (MLR). This process produces predictive modeling of the variables studied. The variables studied in this ozonation process are independent variables consisting of ozone concentration $(\mathrm{mg} / \mathrm{L})$, concentration of dye $(\mathrm{mg} / \mathrm{L}), \mathrm{pH}$ and temperature $\left({ }^{0} \mathrm{C}\right)$. The dependent variables studied were the percentage of dye decolorization. The feasibility of the prediction model used has also been tested using the t-test. Based on the prediction model, $\mathrm{R}^{2}$ values for AO7, AY19, and AB1 dyes are 0.84. 0.87, and 0.93 respectively. The analysis of the influence of the independent variables on the percentage of dye decolorization predicted that the concentration of ozone, dyestuff concentration and $\mathrm{pH}$, significantly influenced the ozonation process of AO7, AY19, and AB1. In the ozonation process the temperature variables have a significant effect on AY19 and AB1, but stronger influence on AO7 ozonation process. Based on the predictions of the influence of each variable, the process in the laboratory can be optimized more effectively and efficiently, so that the cost and time factor can be reduced.
\end{abstract}

\section{Introduction}

The industrial world produces liquid waste resulting from its industrial activities. Paper, pulp, cosmetics, paint, printing, leather, pharmaceuticals, beauty and plastics industries are some of the industries that use synthetic dyes [1]. The use of dye in the process will result in hazardous waste which can endanger life. The dyes used in industrial processes can be classified into two groups, i.e. azo and non-azo groups, where the differences between the two is the presence of the azo group $(-\mathrm{N}=\mathrm{N}-)$. An azo dye has azo groups that can be more than one. While non-azo dye does not have any azo group. Mostly, azo dyestuffs are more widely used than non-azo groups. This is because the azo dye has a complex structure, so that stabilize the staining process, and the product does not quickly fade [2]. Some commonly used azo dyestuffs include Acid Black 1 (AB1), Acid Yellow 19 (AY19), and Acid Orange 7 (AO7) [3]. The characteristics of the three dyestuffs are presented in Table 1.

Through simple handling, azo dyes contained in textile industry waste are very difficult to process, so that appropriate techniques are needed. Currently various techniques for handling textile waste are being developed so that the waste that comes out of the industry is not harmful to the life of water biota. Azo dye waste discharged into rivers or aquatic ecosystems is capable of influencing water transparency, which affects the penetration of sunlight from rivers. Furthermore, they can also be toxic and mutagenic to organisms or aquatic biota.

Table 1. Dye Characteristics

\begin{tabular}{lllll}
\hline Dyes & Formula & Mono/diazo & $\begin{array}{l}\lambda \text { max } \\
(\mathrm{nm})\end{array}$ & $\begin{array}{l}\mathrm{M}_{\mathrm{w}} \\
(\mathrm{g} / \mathrm{mol})\end{array}$ \\
\hline Acid Orange 7 & $\mathrm{C}_{16} \mathrm{H}_{11} \mathrm{~N}_{2} \mathrm{NaO}_{4} \mathrm{~S}$ & Monoazo & 484 & 350,32 \\
\hline Acid Yellow 19 & & & & \\
\hline
\end{tabular}

\footnotetext{
* Corresponding author: sf120@ums.ac.id
} 


Acid Black 1

To overcome the problem, an effective and an efficient technique are needed. One of the techniques currently under development is the use of Advance Oxidizing Process [1]. The Advanced Oxidation Process (AOPs) method has the main advantage of being able to degrade / completely separate nonbiodegradable hazardous compounds in waste through oxidation [2]. This technique uses chemicals such as oxidizing agents or reducing agents as a treatment based on the formation of hydroxyl radicals produced in the oxidation process. Some examples of research that have used this technique are the use of ozone [3], fenton and sono-fenton [4], persulfatehydrogen peroxide [1], combination of ozone and electrolysis [5], peroxydisulfate [2], non-thermal AOPs (Advanced Oxidation Process) [6], photocatalyst-zerovalent/copper [7], $\mathrm{UV} / \mathrm{H}_{2} \mathrm{O}_{2}$ [8]. The AOPs technology is a combination of several process to produce free hydroxyl radicals $(\bullet \mathrm{OH})$. These hydroxyl radicals are selective against pollutants so that they are effectively used to handle textile industry waste. Ozone has a high oxidation rate of $2.08 \mathrm{~V}$ so that it can produce free hydroxyl radicals $(\bullet \mathrm{OH})$. The hydroxyl radicals is considerable powerful to oxidize both organic and non-organic compounds [1].

Some of the variables that affect the degradation efficiency using ozonation include $\mathrm{pH}$, initial concentration of dyestuff, ozone concentration, and temperature. The dye AO7, AY19 and AB1 have different amount of azo bonds, AB1 has two azo bonds while AO7 and AY19 have one azo bond. These differences in the number of azo groups will affect the degradation efficiency of the dyestuff under the same treatment conditions. It has also been investigated using artificial neural network modeling (ANN) by Fatimah et.al [9] that the difference in the number of azo bonds present in the dye affects the percentage of decolorization. In acidic conditions, the ozone molecule is highly selective in attacking the active group of the dyestuff, such as the presence of double bonds or aromatic groups present in the dyestuff. In the basic conditions of hydroxyl radicals are produced from the process of decomposition or decomposition of the dyestuff itself. Under alkaline $\mathrm{pH}$ conditions up to neutral $\mathrm{pH}$, there may be reactions which cannot produce radical reactions of hydroxyl formation. The $\mathrm{pH}$ value of the solution will decrease with the formation of the hydroxyl compound from the ozonation process. The reaction mechanism of the ozonation process is that the ozone reacts directly with the dyestuff through the ozonolysis process and through the formation of a radical chain. The reaction between ozone and anion hydroxide to intermediate radicals and hydroxyl radicals is essential in the oxidation process of this dye [10].
The degradation efficiency of the ozonation process can be done systematically by testing each variable by making the other variable fixed. This is done repeatedly for several times to produce maximum efficiency. Repetition of this experiment will require time and it can be very costly. The prediction on the strength of the influence of the variables of each experiment can be determined so that it can optimize the existence of each variable. To analyze the performance of the degradation process through ozonation, method of analysis of Multiple Linear Regresion (MLR) can be used. MLR analysis investigated a linear relationship between two or more independent variables $\left(\mathrm{X}_{1}, \mathrm{X}_{2}, \ldots . \mathrm{X}_{\mathrm{n}}\right)$ with the dependent variable (Y). This analysis is to reveal the direction of the relationship between independent variables and dependent variables, whether each independent variable has positive or negative effects, and to predict the value of the dependent variable if the value of the independent variable increases or decreases [11]. The data used are usually scaled intervals or ratios. This method involved the development of a single or simple regression. This study used independent variables consisting of 4 parameters namely the concentration of ozone $(\mathrm{mg} / \mathrm{L})$, concentration of dye $(\mathrm{mg} / \mathrm{L}), \mathrm{pH}$, and temperature $\left({ }^{0} \mathrm{C}\right)$. The dependent variable consists of one parameter only that was the percentage of decolourization $(\%)$.

The MLR model of dyestuff decolorization by using adsorption has been performed by Ho et.al [12]. This study only analyzed the data set by using Chi square so that the power between variables were not explained in detail. Another study by Muthukumar et.al [13] describes the effect of active groups on some dyes on COD values using $\mathrm{UV} / \mathrm{H}_{2} \mathrm{O}_{2}$ modeled by statistical tests. To determine the effect of the dye strength on the fabric have been modeled with MLR also by Timofei et.al [14] and Wang et.al [15]. The MLR application is also used by Yao et.al [16] to find out how much the molecular structure affects molecular activity.

Referring to the previous research, it was proposed to use MLR to find out how much influence of each of the variables in the process of dye decolourization in ozonation. From the results of this analysis, it could be known which variables were the most dominant influence so that it would become possible to manage the time and costs in waste processing.

\section{Material and Method}

\subsection{Material}

In this study the data used were secondary data obtained from research that has been done by Kasiri 
et.al [17]. The parameters used in analyzing this model consisted of 4 parameters as the independent variable and 1 parameter as the dependent variable. Independent variables consisted of ozone concentration $(\mathrm{mg} / \mathrm{L})$, concentration of dye $(\mathrm{mg} / \mathrm{L})$, $\mathrm{pH}$, and temperature $\left({ }^{\circ} \mathrm{C}\right)$. The dependent variable consisted of the percentage value of decolorization.

\subsection{Experimental design}

Secondary data obtained was processed by using software SPSS version 23. In this research Multiple Linear Regression analysis (MLR) was used. The advantages of using the MLR was that we are able to determine how much influence of independent variables to dependent variables. MLR model can be written in Equation 1. In the design of this study each variable is encoded into a symbol that it was so easy to interpret.

$Y=\alpha_{0}+\alpha_{1} X_{1}+\alpha_{1} X_{2}+\alpha_{2} X_{3}+\alpha_{3} X_{4}$

Explain:

$\mathrm{Y} \quad$ : Percentage of decolorisation (\%)

$\alpha_{0} \quad$ : Constanta or Determination Coefficients

$\alpha_{1} \quad$ : Coefficient regression for ozone concentration

$\alpha_{2} \quad$ : Coefficient regression for dyes concentration

$\alpha_{3} \quad$ : Coefficient regression for $\mathrm{pH}$

$\alpha_{4} \quad$ : Coefficient regression for temperature

$X_{1} \quad$ : ozone concentration $(\mathrm{mg} / \mathrm{L})$

$X_{2} \quad$ : dyes concentration $(\mathrm{mg} / \mathrm{L})$

$X_{3} \quad: \mathrm{pH}$

$X_{4} \quad$ : temperature $\left({ }^{\circ} \mathrm{C}\right)$

\subsection{Parameter analysed}

The determination analysis in multiple linear regression is used to know the percentage of contribution of independent variables $\left(X_{1}, X_{2}, X_{3}\right.$, $X_{n}$ ) simultaneously to the dependent variable (Y). This coefficient shows how much percentage of variation of independent variable used in the model was able to explain variation of dependent variable. The value of $\mathrm{R}^{2}$ equals 0 , so there was no percentage contribution of the influence given by the independent variable to the dependent variable, or the variation of the independent variable used in the model did not explain the slightest variation of the dependent variable. On the contrary, when $\mathrm{R}^{2}$ equals 1 , the percentage of contribution given by the independent variable to the dependent variable is perfect, or the variation of the independent variable used in the model explains $100 \%$ variation of the dependent variable. This experiment also analyzed ANOVA from each of the equations obtained. If the significance value of ANOVA $<0.05$ then the regression equation used is feasible. To find out which variable is most influential and the possibility of unused variable then used enter method, which putting all the variables into the analysis at once [11].

\section{Result and Discussion}

The AOPs (Advance Oxidation Process) technique involves oxidation reactions sourced from ozone $\left(\mathrm{O}_{3}\right)$ in solution to produce free hydroxyl radical $\infty H$. This hydroxyl radical has a very large role in oxidizing the dye so that it can decrease the presence of the dyestuff. Ozone has an unstable oxygen element, so it is very reactive. This can be explained in the following reaction:

$$
\begin{array}{lll}
\mathrm{O}_{2}+U V \text { or } h \mathrm{v}<310 \mathrm{~nm} \rightarrow & \bullet \mathrm{O} \\
\bullet \mathrm{O}+\mathrm{O}_{2} \rightarrow \mathrm{O}_{3} &
\end{array}
$$

Species of $\bullet \mathrm{O}$ is radical so that when it collided with water, it will form hydroxyl ions $\left(\mathrm{OH}^{-}\right)$, thus forming a radical $\cdot \mathrm{OH}$, which in turn will play a role in overhauling the bonds of the dyestuff compounds.

Parameters used in this ozonation process are ozone concentration $(\mathrm{mg} / \mathrm{L})$, concentration of dye $(\mathrm{mg} / \mathrm{L}), \mathrm{pH}$ and temperature $\left({ }^{\circ} \mathrm{C}\right)$. Each variable parameter has an influence with different dominance. To know how was the big influence of each variable, this was done by MLR analysis. Based on the MLR equation using the enter method, the data obtained as shown in Table 2. As shown on Table 2, the obtained values of $\mathrm{R}^{2}$ for AO7, AY19, AB1 are equal to 0.84, 0.87, and 0.93. This shows that the effect of free variable to the percentage value of dye decolorization are $84 \%, 87 \%$, and $93 \%$ respectively. The rest of the whole $100 \%$ value are the influence of other than ozone concentration, dye concentration, $\mathrm{pH}$, and temperature. The $p$-value of the ANOVA test of each dye is $<0.005$. This indicates that this regression equation could be used to analyze the influence of independent variable to decolorization percentage. The regression equation for each dye is shown in Table 2.

\begin{tabular}{|c|c|c|c|}
\hline Dyes & $\mathrm{R}^{2}$ & Sig.ANV & Regresion equation \\
\hline $\mathrm{AO} 7$ & 0,84 & 0,000 & $Y=23,328-0,001 X_{1}-0,650 X_{2}+4,556 X_{3}+6,50 X_{4}$ \\
\hline AY19 & 0,87 & 0,000 & $Y=49,473+0,005 X_{1}-0,708 X_{2}+4,167 X_{3}+0,46 X_{4}$ \\
\hline AB1 & 0,93 & 0,000 & $Y=73,546+0,006 X_{1}-0,775 X_{2}+7 X_{3}-0,483 X_{4}$ \\
\hline
\end{tabular}

Table 2. The Result of Statistical MLR Equations 
Based on the correlation significance test in Table 3 , it was found that in the ozonation process of AO7, the influence of concentration $\mathrm{O}_{3}$ exert a relatively small effect on this process. The most influential variables in this process are the concentration of $\mathrm{AO} 7$, $\mathrm{pH}$ and temperature. It can be explained that for the addition of $1 \mathrm{mg} / \mathrm{L}$ of dye concentration, with increased the $\mathrm{pH}$ conditions and increased in temperature, will increase the percentage of decolorization. The resulting hydroxyl radical can increase the effectiveness of decolorization. In the process of analysis of the effect of independent variables on ozonation AY19, it was obtained that the concentration variable AY19 and $\mathrm{pH}$ is the variable that gave the most significant influence.
With the increase in $\mathrm{pH}$ then the percentage of decolorization will be greater. It can be explained that in AY19 there are two sulphonic acid groups and the presence of chlorine and methyl groups. The presence of these constituents will affect the formation of hydroxyl radicals. In the process of ozonation $\mathrm{AB} 1$ the most influential variable is the concentration of $\mathrm{AB} 1$, $\mathrm{pH}$, and temperature. $\mathrm{AB} 1$ structure contains two sulphonic acid groups, one nitro and amine group. This, of course, affects the presence of hydroxyl radicals resulting from the ozonation process. The more the amount of substituents in the dye causes the decolorization process to become more chalenging and require the other variable to be more effective.

Table 3. The Significance of Correlation

\begin{tabular}{|c|c|c|c|c|c|c|}
\hline \multirow[t]{2}{*}{ Dye } & \multirow{2}{*}{ Paramaters } & \multicolumn{5}{|c|}{ Correlation } \\
\hline & & {$\left[\mathrm{O}_{3}\right]$} & [dye] & $\mathrm{pH}$ & $\mathrm{T}$ & Constanta \\
\hline \multirow[t]{2}{*}{$\mathrm{AO} 7$} & p-value (Sig.) & 0,845 & 0,000 & 0,000 & 0,016 & 0,55 \\
\hline & $\mathrm{t}$ & $-0,197$ & $-5,133$ & 5,396 & 2,567 & 2,013 \\
\hline \multirow[t]{2}{*}{ AY19 } & p-value (Sig.) & 0,403 & 0,000 & 0,000 & 0,112 & 0,000 \\
\hline & $\mathrm{t}$ & 0,850 & $-5,272$ & 7,143 & $-1,644$ & 5,466 \\
\hline \multirow[t]{2}{*}{$\mathrm{AB} 1$} & p-value (Sig.) & 0,164 & 0,000 & 0,000 & 0,005 & 0,000 \\
\hline & $\mathrm{t}$ & 1,434 & $-9,373$ & 8,271 & 3,088 & 7,513 \\
\hline
\end{tabular}

The resulting analysis showed that the $\mathrm{pH}$ factor played a most significant role in the ozonation processes of $\mathrm{AO} 7, \mathrm{AY} 19$, and $\mathrm{AB} 1$. In acidic $\mathrm{pH}$ the ozone is available as molecular ozone and in alkaline $\mathrm{pH}$ it decomposes into secondary free radicals such as $\cdot \mathrm{OH}$ and $\cdot \mathrm{HO}_{2}[18]$.

$$
\begin{aligned}
& \bullet \mathrm{O}_{2}^{-}+\mathrm{H}^{+} \rightarrow \cdot \mathrm{HO}_{2} \\
& 2 \cdot \mathrm{HO}_{2} \rightarrow \mathrm{H}_{2} \mathrm{O}_{2}+\mathrm{O}_{2} \\
& \mathrm{H}_{2} \mathrm{O}_{2}+\cdot \mathrm{O}_{2}{ }^{-} \rightarrow \cdot \mathrm{HO}+\mathrm{O}_{2}+\mathrm{OH}^{-} \\
& \mathrm{H}_{2} \mathrm{O}_{2}+\mathrm{hu} \rightarrow 2 \cdot \mathrm{HO}_{2}
\end{aligned}
$$

Even though hydroxyl radical has a higher oxidation potential than ozone its selectivity is much less. The oxidizing potential of ozone decrease from $2,8 \mathrm{~V}$ in acidic $\mathrm{pH}$ to $1,4 \mathrm{~V}$ in alkaline solution. This indicates that the ozone stability decrease with increasing $\mathrm{pH}$, it results in the generation of secondary free radicals.

\section{Conclusion}

Analysis of the effect of free variables on dye decolorization of AO7, AY19, and AB1 can use Multiple Linear Regression method. This MLR equation is effective in determining the most significant independent variables affecting the dye decolorization process. Based on the analysis, the variable of dyestuff concentration and $\mathrm{pH}$ is the most influential factor on this process. Temperature variables significantly influence the decolorization of AY19 and AB1, whereas at AO7 the temperature variables have more significant effect. This equation can be conditioned for laboratory research so that it can be regulated by technical procedures that affect time and cost.

\section{References}

1. S. Yang et al., "Degradation efficiencies of azo dye Acid Orange 7 by the interaction of heat, UV and anions with common oxidants: Persulfate, peroxymonosulfate and hydrogen peroxide," $J$. Hazard. Mater., vol. 179, no. 1-3, pp. 552-558, Jul. 2010.

2. H. Lin, H. Zhang, and L. Hou, "Degradation of C. I. Acid Orange 7 in aqueous solution by a novel electro/Fe3O4/PDS process," J. Hazard. Mater., vol. 276, pp. 182-191, Jul. 2014.

3. M. B. Kasiri, N. Modirshahla, and H. Mansouri, "Decolorization of organic dye solution by ozonation; Optimization with response surface methodology," Int. J. Ind. Chem., vol. 4, no. 1, p. 3, 2013.

4. E. Basturk and M. Karatas, "Advanced oxidation of Reactive Blue 181 solution: A comparison between Fenton and Sono-Fenton Process," Ultrason. Sonochem., vol. 21, no. 5, pp. 18811885, Sep. 2014.

5. X.-C. Ruan, M.-Y. Liu, Q.-F. Zeng, and Y.-H. Ding, "Degradation and decolorization of reactive red $\mathrm{X}-3 \mathrm{~B}$ aqueous solution by ozone integrated

* Corresponding author: sf120@ums.ac.id 
with internal micro-electrolysis," Sep. Purif. Technol., vol. 74, no. 2, pp. 195-201, Aug. 2010.

6. B. Jiang, J. Zheng, Q. Liu, and M. Wu, "Degradation of azo dye using non-thermal plasma advanced oxidation process in a circulatory airtight reactor system," Chem. Eng. J., vol. 204-206, pp. 32-39, Sep. 2012.

7. Y. Yuan et al., "Removal of High-Concentration C.I. Acid Orange 7 from Aqueous Solution by Zerovalent Iron/Copper $(\mathrm{Fe} / \mathrm{Cu})$ Bimetallic Particles," Ind. Eng. Chem. Res., vol. 53, no. 7, pp. 2605-2613, Feb. 2014.

8. J. Sun et al., "Degradation of azo dye Acid black 1 using low concentration iron of Fenton process facilitated by ultrasonic irradiation," Ultrason. Sonochem., vol. 14, no. 6, pp. 761-766, Sep. 2007.

9. S. Fatimah and W. Wiharto, "The use of artificial neural network for modeling the decolourization of acid orange 7 solution of industrial by ozonation process," IOP Conf. Ser. Mater. Sci. Eng., vol. 172, p. 12052, Feb. 2017.

10. J. Hrubec, Ed., Quality and Treatment of Drinking Water II, vol. 5 / 5C. Berlin, Heidelberg: Springer Berlin Heidelberg, 1998.

11. W. Wiharto, H. Kusnanto, and H. Herianto, "Hybrid System of Tiered Multivariate Analysis and Artificial Neural Network for Coronary Heart Disease Diagnosis," Int. J. Electr. Comput. Eng. IJECE, vol. 7, no. 2, pp. 1023-1031, 2017.

12. Y.-S. Ho, W.-T. Chiu, and C.-C. Wang, "Regression analysis for the sorption isotherms of basic dyes on sugarcane dust," Bioresour. Technol., vol. 96, no. 11, pp. 1285-1291, Jul. 2005.
13. M. Muthukumar, D. Sargunamani, and N. Selvakumar, "Statistical analysis of the effect of aromatic, azo and sulphonic acid groups on decolouration of acid dye effluents using advanced oxidation processes," Dyes Pigments, vol. 65, no. 2, pp. 151-158, May 2005.

14. S. Timofei, L. Kurunczi., and T. Suzuki, "Multiple Linear Regression (MLR) and Neural Network (NN) calculations of some disazo dye adsorption on cellulose," Dyes Pigments, vol. 34, no. 3, pp. 181-193, Jul. 1997.

15. X. Wang et al., "Quantitative structure-affinity relationship study of azo dyes for cellulose fibers by multiple linear regression and artificial neural network," Chemom. Intell. Lab. Syst., vol. 134, pp. 1-9, May 2014.

16. X. J. Yao et al., "Comparative Study of QSAR/QSPR Correlations Using Support Vector Machines, Radial Basis Function Neural Networks, and Multiple Linear Regression," $J$. Chem. Inf. Comput. Sci., vol. 44, no. 4, pp. $1257-$ 1266, Jul. 2004

17. M. B. Kasiri, N. Modirshahla, and H. Mansouri, "Decolorization of organic dye solution by ozonation; Optimization with response surface methodology," Int. J. Ind. Chem., vol. 4, no. 1, pp. 1-10, 2013.

18. T. Setyaningtyas and D. W. Dwiasi, "Degradasi Zat Warna Azo Tartrazin Pada Limbah Cair Mie Dengan Metode AOPs (Advanced Oxidation Processes)," Molekul, vol. 7, no. 2, pp. 153-162, 2012. 